\title{
The prognostic effect of adjuvant chemotherapy in the colon cancer patients with solitary lymph node metastasis
}

\author{
Seung-Seop Yeom ${ }^{1} \cdot$ Soo Young Lee ${ }^{1} \cdot$ Chang Hyun Kim ${ }^{1} \cdot$ Hyeong Rok Kim ${ }^{1} \cdot$ Young Jin Kim ${ }^{1}$
}

Accepted: 3 July 2019 / Published online: 10 July 2019

(C) The Author(s) 2019

\begin{abstract}
Purpose Previous studies have reported paradoxical survival prognoses for some node-negative and node-positive colon cancer patients. However, current guidelines recommend adjuvant chemotherapy (CT) only for node-positive patients. This study investigated the efficacy of adjuvant CT for patients who underwent radical surgery for colon cancer with solitary lymph node (LN) metastasis.

Methods This study included 281 patients treated between 2004 and 2015. Patients were classified into no-CT $(n=39)$ and CT $(n=242)$ groups, and the survival outcomes and recurrence-related follow-up data were analyzed.

Results The groups exhibited similarities in tumor sidedness, tumor differentiation, and pathologic stage. However, the age, ASA class, and preoperative CEA level were relatively lower in the CT group. Although the CT group had a higher 5-year overall survival (OS) rate than the no-CT group $(88.4 \%$ vs. $65.3 \%, p<0.001)$, the groups did not differ in terms of 5 -year disease-free survival (DFS) $(\mathrm{CT}, 84.1 \%$ vs. no-CT, $83.3 \%, p=0.490)$. A multivariate analysis identified adjuvant $\mathrm{CT}$ as an independent factor for OS but not for DFS. A highly examined LN count $(\geq 12)$ was associated with improved DFS improvement. However, D3 LN dissection was not associated with DFS or OS. For DFS, intermediate/apical positive LNs received a high hazard ratio relative to pericolic/epicolic LNs (2.080, 95\% confidence interval: 0.979-4.416), but this was not significant $(p=0.057)$.

Conclusions Adjuvant chemotherapy did not provide clear advantages for colon cancer with solitary LN metastasis. Further large studies that analyze several prognostic factors are needed to establish tailored adjuvant CT administration guidelines.
\end{abstract}

Keywords Colon cancer $\cdot$ Adjuvant chemotherapy $\cdot$ Solitary lymph node metastasis $\cdot$ Single lymph node metastasis

\section{Introduction}

Colorectal cancer treatment is determined by disease stage. Currently, surgery is the only curative treatment, although adjuvant chemotherapy (CT) also plays an important role based on the extent of disease. Lymph node (LN) metastasis is among the most important factors used to determine the stage and prognosis of colorectal cancer. However, several

Electronic supplementary material The online version of this article (https://doi.org/10.1007/s00384-019-03346-7) contains supplementary material, which is available to authorized users.

Hyeong Rok Kim drkhr@jnu.ac.kr

1 Department of Surgery, Chonnam National University Hwasun Hospital and Medical School, 322 Seoyang-ro Hwasun-eup, Hwasun-gun Jeonnam, Hwasun 58128, South Korea studies have reported better prognoses with some nodepositive colon cancers (stage IIIa) than with some nodenegative cancers (high-risk stage II) [1-3]. Although the efficacy of adjuvant $\mathrm{CT}$ for high-risk stage II cancers has not been proven, the current treatment guidelines appear to be contradictory because all of the node-positive colon cancer patients receive $\mathrm{CT}$, regardless whether their prognosis is superior to that of the high-risk stage II patients.

It has been documented that most of the LN metastases involve the epicolic or pericolic LNs near the tumor, whereas metastases rarely occur in LNs $>10 \mathrm{~cm}$ distal from the tumor [4]. Therefore, the oncologic outcome of the colon cancer with a solitary LN metastasis may be favorable to that of a case with several LN metastases because of the smaller tumor volume in the lymphatic channel. In such cases, radical surgery might be curative without adjuvant CT, but there are not enough studies about the efficacy of the chemotherapy for colon cancer with solitary LN metastasis. To date, only one study based on the database of the Northern and Yorkshire 
Cancer Registry and Information Service (NYCRIS) evaluated the efficacy of adjuvant $\mathrm{CT}$ for colon cancer with solitary LN metastasis [5]. The researchers analyzed 480 colon cancer patients with solitary LN metastasis and documented a positive effect of adjuvant CT. However, the efficacy of CT was not the primary end point of their study, and the researchers did not control related factors. Furthermore, too few LNs were examined in that study population (mean $11.3 \mathrm{LNs}$ ), and $28 \%$ of rectal cancer patients included in that analysis could have received different treatments such as perioperative chemoradiotherapy or radiotherapy. A small number of examined LNs has been associated with inappropriate cancer staging, and there are differences in characteristics and treatment outcomes between colon and rectal cancer [6]. Therefore, further analyses are needed to verify the efficacy of adjuvant CT for colon cancer with solitary LN metastasis.

In this study, we aimed to determine the effects of the positive LN location and extent of LN dissection on the prognosis of colon cancer patients with solitary LN metastasis after adjuvant $\mathrm{CT}$. We also aimed to verify whether colon cancer with a solitary LN metastasis could be differentiated from other stage III colon cancers in terms of treatment. To our knowledge, this is the first study to investigate the efficacy of adjuvant CT for colon cancer with solitary LN metastasis by analyzing the risk factors associated with survival outcomes, including the surgical extent and several clinicopathological factors.

\section{Patients and methods}

\section{Study population and collected data}

The study population comprised colon cancer patients with solitary LN metastasis who underwent surgery between 2004 and 2015 at a single tertiary cancer center in South Korea. Patients diagnosed with familial adenomatous polyposis, hereditary nonpolyposis colorectal cancer, rectal cancer, benign colonic masses, or nonadenocarcinoma histology were excluded (Fig. 1). The population was divided into two groups: those who did and did not receive adjuvant $\mathrm{CT}$ (CT and no-CT groups). Clinicopathological variables, LN status (examined LN count, locations of positive LN, and extent of LN dissection), adjuvant CT history, and recurrence data were retrieved from a prospectively collected database and reviewed. The clinicopathological factors included age, sex, tumor size, tumor sidedness, obstruction, or microperforation identified clinically via colonoscopy or computed tomography, preoperative carcinoembryonic antigen (CEA) levels, cancer cell differentiation, pathologic $\mathrm{T}$ category (pT), lymphovascular invasion (LVI), and perineural invasion (PNI).

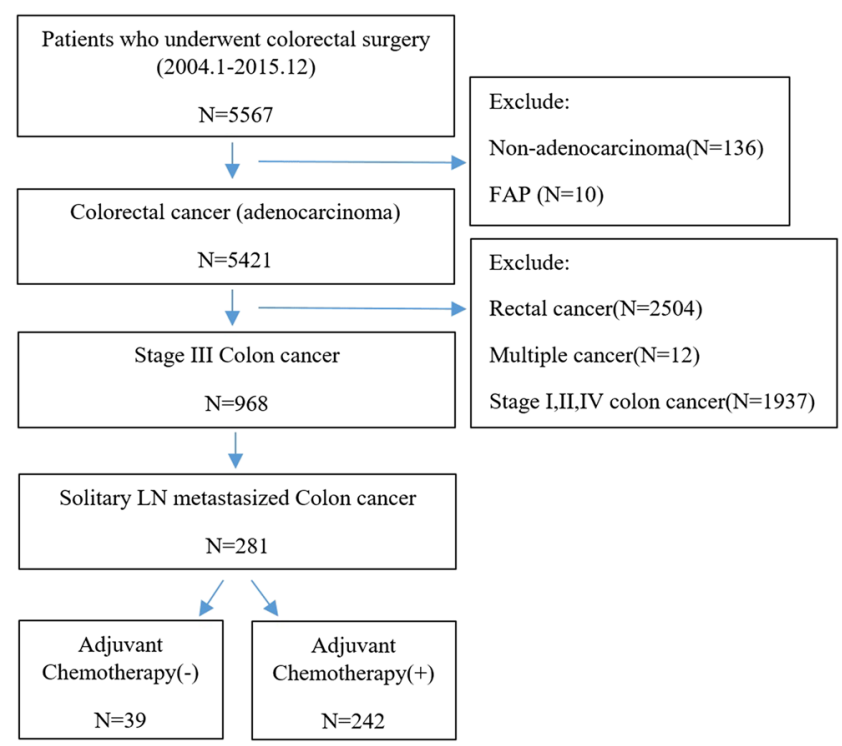

Fig. 1 Flow chart of case selection

\section{Operative procedures}

Generally, we considered D3 LN dissection for advanced colon cancers. The root of the ileocolic pedicle, right colic pedicle, and right branch of the mid-colic pedicle were dissected for ascending colon cancers. The mid-colic pedicles were ligated for hepatic flexure and proximal to mid transverse colon cancers. In all such cases, mid-colic LN sampling or dissection was performed when enlarged mid-colic lymph nodes were detected on preoperative computed tomography scans. The root of the left branch of the mid-colic artery and the left colic artery were ligated for distal transverse, splenic flexure, and proximal descending colon cancers. Inferior mesenteric arteries were ligated at the origin for sigmoid colon cancers. D2 LN dissections were also considered for cases involving suspected clinical stage I or II tumors.

\section{Endpoints during follow-up}

All patients were regularly followed for 5 years postoperatively. CEA measurements and abdominal computed tomography were performed every 3-6 months. Chest-computed tomography was performed annually. Colonoscopy was performed during the first, third, and last years of follow-up. Adjuvant $\mathrm{CT}$ was recommended for all patients with $\mathrm{LN}$ metastasis. The follow-up period ended when the subject developed a newonset recurrence, died, or survived beyond December 31, 2018. The main outcomes of this study were the recurrence, disease-free survival (DFS), and overall survival (OS) rates. The survival analysis included death by any cause as an event. All deaths were confirmed by referencing the National Death Registry of South Korea. The type of CT regimen and treatment for recurrence were also investigated. 


\section{Statistical analysis}

The clinicopathological variables, surgical variables, adjuvant CT history, and treatment of recurrence were compared using a cross-table analysis, Fisher's exact test with two-sided verification, or Pearson's Chi-square test with an unpaired $t$ test as appropriate. The influence of each variable on patient survival was calculated using the Kaplan-Meier method, and significant differences between survival durations were evaluated using the log-rank test. The prognostic relevance of each studied factor was determined using univariate and multivariate Cox regression analyses. The selection of variables for the multivariate analysis considered both statistical and clinical importance. Statistical significance was defined as a $p$ value $<0.05$. All calculations were performed using SPSS software (version 22, SPSS Inc., Chicago, IL, USA).

\section{Results}

\section{Patient characteristics}

Of the 281 included colon cancer patients with solitary LN metastasis, $85.1 \%(n=239)$ presented with positive LNs near the colon (epicolic or pericolic area); the remainder involved positive LNs in the intermediate or apical area (intermediate LNs: $n=38$, apical LNs: $n=4$ ) (Fig. 2). A mean of 33.0 LNs were examined in each case, and D3 LN dissections were performed in $>85 \%$ cases.

Moreover, $86.1 \%(n=242)$ of patients and $13.9 \%$ $(n=39)$ were classified into the CT and no-CT groups, respectively. The median age $(65.5$ vs. 76.0 years, $p<0.001$ ), number of patients with high American Society of Anesthesiologists class (ASA I or II; 95.5\% vs. $79.5 \%, p=0.002$ ), and proportion of patients with an elevated preoperative CEA level $(33.5 \%$ vs. $53.8 \%$, $p=0.019)$ were lower in the CT group than in the noCT group. However, the groups did not differ significantly in terms of sex, body mass index, tumor sidedness, tumor size, tumor cell type, pT, LVI, PNI, and clinical obstruction or perforation. Furthermore, the groups did not differ significantly in terms of the surgery type (open or laparoscopic), number of examined $\mathrm{LN}$, and locations of positive LN (Table 1).

\section{Disease-free survival}

The CT and no-CT groups did not differ significantly in terms of the 2-year and 5-year DFS rates (2-year DFS: $88.1 \%$ vs. $83.5 \%$; 5 -year DFS: $84.1 \%$ vs. $83.3 \%, p=$ 0.490) (Fig. 3a). A multivariate analysis identified a large tumor size $(\geq 4 \mathrm{~cm})$, elevated preoperative CEA level $(>5 \mathrm{ng} / \mathrm{ml})$, and number of examined LN $(\geq 12)$ as factors independently associated with DFS. However, pT, tumor cell type, LVI, PNI, clinical obstruction or perforation, locations of positive LN (epicolic/pericolic LN vs. intermediate/apical LN), and history of adjuvant CT were not associated with DFS (Table 2).

\section{Overall survival}

In contrast to the DFS rates, the CT group had significantly higher 2-year and 5-year OS rates than the noCT group (2-year OS: $94.8 \%$ vs. $75.7 \%$; 5-year OS: $88.4 \%$ vs. $65.3 \%, p<0.001$ ) (Fig. $3 b$ ). A multivariate analysis identified an older age ( $>70$ years), large tumor size $(\geq 4 \mathrm{~cm})$, elevated preoperative CEA level (> $5 \mathrm{ng} / \mathrm{ml}$ ), LVI, PNI, and history of adjuvant CT as independent factors associated with OS. Again, however,
Fig. 2 Locations of positive lymph nodes

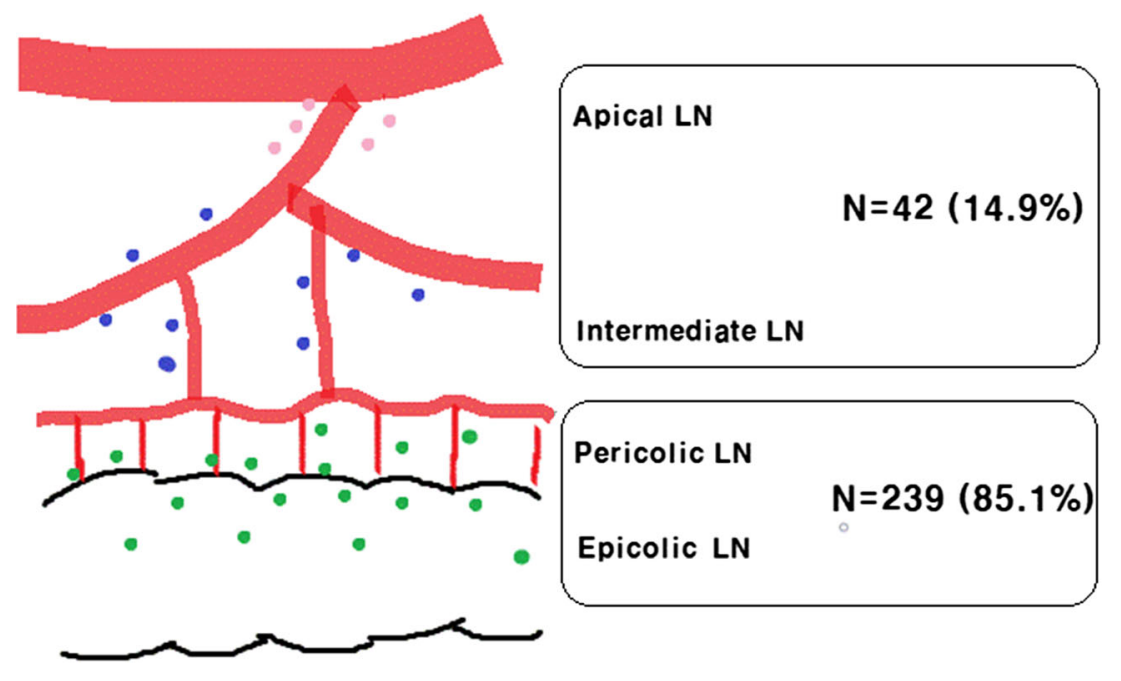


Table 1 Characteristics of patients according to adjuvant chemotherapy administration

\begin{tabular}{|c|c|c|c|}
\hline Variables & Adjuvant chemotherapy $(+)(n=242)$ & Adjuvant chemotherapy $(-)(n=39)$ & $p$ \\
\hline $\mathrm{F} / \mathrm{U}$ duration, month, median (range) & $55.0(0-231)$ & $27.6(0-83)$ & $<.001$ \\
\hline \multicolumn{4}{|l|}{ Age, years } \\
\hline Median (range) & $65.5(30-85)$ & $76.0(35-92)$ & $<.001$ \\
\hline $\begin{array}{l}<70 \\
\geq 70\end{array}$ & $\begin{array}{r}153(63.2 \%) \\
89(36.8 \%)\end{array}$ & $\begin{array}{c}8(20.5 \%) \\
31(79.5 \%)\end{array}$ & $<.001$ \\
\hline Gender, male, $n(\%)$ & $125(51.7 \%)$ & $19(48.7 \%)$ & 0.863 \\
\hline \multicolumn{3}{|l|}{ BMI } & \multirow[t]{3}{*}{0.199} \\
\hline$<25$ & $158(65.3 \%)$ & $30(76.9 \%)$ & \\
\hline$\geq 25$ & $84(34.7 \%)$ & $9(23.1 \%)$ & \\
\hline \multicolumn{3}{|l|}{ ASA class, $n(\%)$} & \multirow[t]{3}{*}{0.002} \\
\hline I, II & $231(95.5 \%)$ & $31(79.5 \%)$ & \\
\hline III, IV & $11(4.5 \%)$ & $8(20.5 \%)$ & \\
\hline \multicolumn{3}{|l|}{ Tumor sidedness, $n(\%)$} & \multirow[t]{3}{*}{0.296} \\
\hline Right & $100(41.3 \%)$ & $20(51.3 \%)$ & \\
\hline Left & $142(58.7 \%)$ & $19(48.7 \%)$ & \\
\hline \multicolumn{3}{|l|}{ Preoperative CEA level, $n(\%)$} & \multirow[t]{3}{*}{0.019} \\
\hline$\leq 5 \mathrm{ng} / \mathrm{ml}$ & $161(66.5 \%)$ & $18(46.2 \%)$ & \\
\hline$>5 \mathrm{ng} / \mathrm{ml}$ & $81(33.5 \%)$ & $21(53.8 \%)$ & \\
\hline Tumor size, $\mathrm{cm}$, median (range) & $4.5(0.5-9.0)$ & $5.0(0.7-9.0)$ & 0.124 \\
\hline \multicolumn{3}{|l|}{ Cell type, $n(\%)$} & \multirow[t]{3}{*}{0.171} \\
\hline $\mathrm{WD} / \mathrm{MD}$ & $227(93.8 \%)$ & $34(87.2 \%)$ & \\
\hline $\mathrm{PD} / \mathrm{MUC}$ & $15(6.2 \%)$ & $5(12.8 \%)$ & \\
\hline \multicolumn{3}{|l|}{ Pathologic T, $n(\%)$} & \multirow[t]{5}{*}{0.547} \\
\hline 1 & $17(7.0 \%)$ & $1(2.6 \%)$ & \\
\hline 2 & $28(11.6 \%)$ & $3(7.7 \%)$ & \\
\hline 3 & $155(64.0 \%)$ & $29(74.4 \%)$ & \\
\hline 4 & $42(17.4 \%)$ & $6(15.4 \%)$ & \\
\hline LVI, $n(\%)$ & $63(26.0 \%)$ & $10(25.6 \%)$ & 1.000 \\
\hline PNI, $n(\%)$ & $99(40.9 \%)$ & $18(46.2 \%)$ & 0.601 \\
\hline Obstruction, $n(\%)$ & $15(6.2 \%)$ & $4(10.3 \%)$ & 0.314 \\
\hline Perforation, $n(\%)$ & $1(0.4 \%)$ & 0 & 1.000 \\
\hline \multicolumn{3}{|l|}{ Surgery type, $n(\%)$} & \multirow[t]{3}{*}{0.23} \\
\hline Open & $35(14.5 \%)$ & $9(23.1 \%)$ & \\
\hline Laparoscopic & $207(85.5 \%)$ & $30(76.9 \%)$ & \\
\hline \multicolumn{3}{|l|}{ LN dissection, $n(\%)$} & \multirow[t]{3}{*}{1.00} \\
\hline D2 & $36(14.9 \%)$ & $6(15.4 \%)$ & \\
\hline D3 & $206(85.1 \%)$ & $33(84.6 \%)$ & \\
\hline \multicolumn{4}{|l|}{ Examined LN counts, $n(\%)$} \\
\hline Mean (range) & $32.8(2-122)$ & $34.3(4-81)$ & 0.639 \\
\hline $\begin{array}{l}<12 \\
\geq 12\end{array}$ & $\begin{array}{c}21(8.7 \%) \\
221(91.3 \%)\end{array}$ & $\begin{array}{c}2(5.1 \%) \\
37(94.9 \%)\end{array}$ & 0.752 \\
\hline Location of positive LN (intermediate/apical) & $38(15.7 \%)$ & $4(10.3 \%)$ & 0.474 \\
\hline
\end{tabular}

$L N M$ lymph node metastasis, ASA American Society of Anesthesiologists, $C E A$ carcinoembryonic antigen, $W D$ well differentiated, $M D$ moderately differentiated, $P D$ poorly differentiated, $M U C$ mucinous carcinoma, $L V I$ lymphovascular invasion, $P N I$ perineural invasion

*Significant $P$ values $(<0.05)$ are in italics 

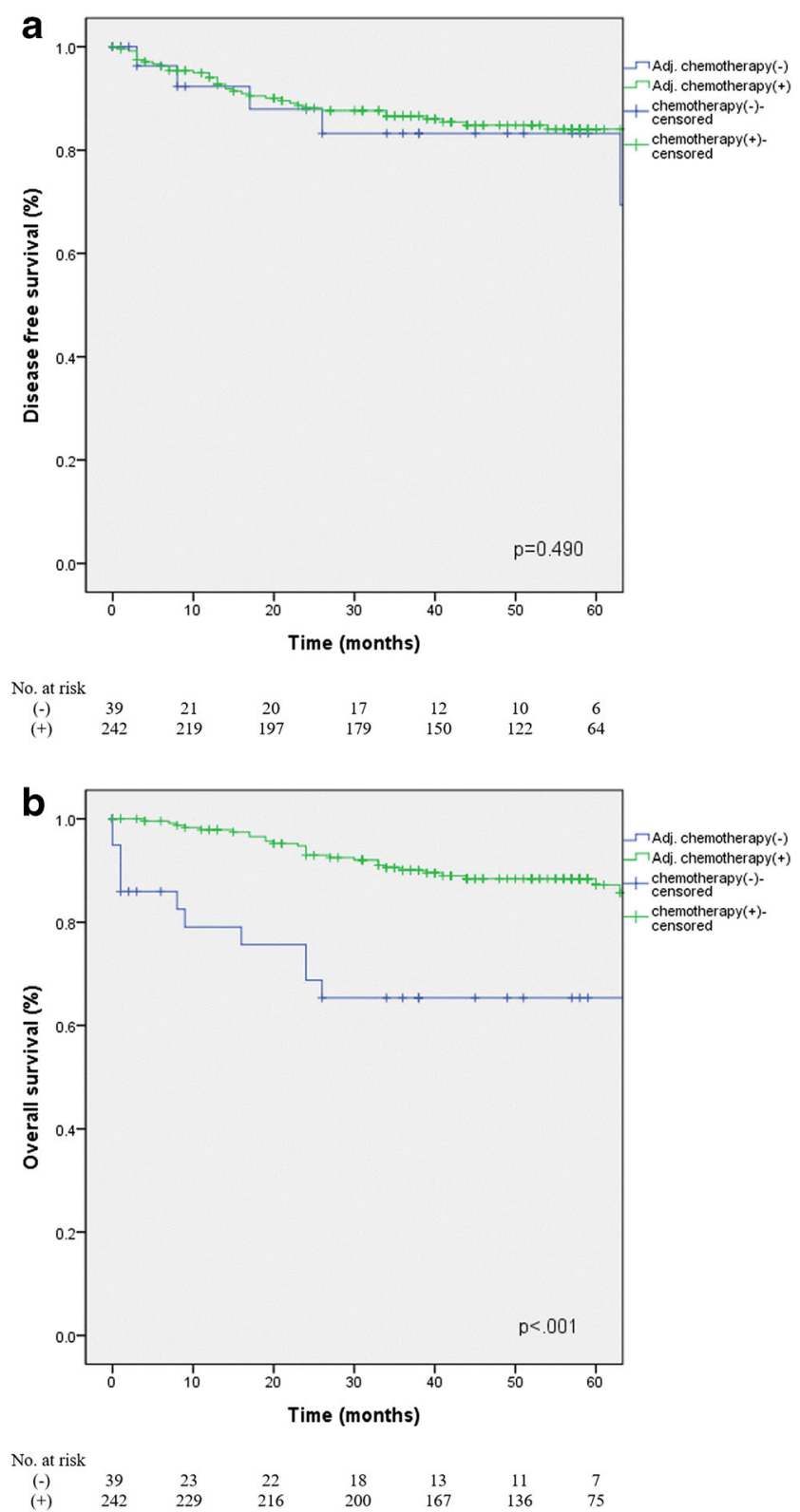

Fig. 3 a Disease-free survival and $\mathbf{b}$ overall survival rates according to the use of adjuvant chemotherapy

pT, tumor cell type, and location of positive LN were not associated with OS (Table 3).

\section{Rates of recurrence and salvage treatments}

Forty patients developed recurrences. The 5-year recurrence rate $(14.5 \%$ vs. $12.8 \%, p=1.000)$ and recurrence pattern $(p=$ 1.000) did not differ significantly between the $\mathrm{CT}$ and no-CT groups (Table 4). Most patients in the CT group received treatment for recurrence (any treatment vs. no treatment: $91.4 \%$ vs. $8.6 \%$ ), whereas many in the no-CT group failed to receive or rejected treatment for recurrence (any treatment vs. no treatment: $20 \%$ vs. $80 \%$ ) (Table 4 ).

\section{CT regimen and survival outcome}

Four types of adjuvant $\mathrm{CT}$ regimens were administered to the 242 patients in the CT group: 5-fluorouracil (5-FU) + leucovorin $(n=85)$; capecitabine plus oxaliplatin (XELOX) or 5-FU plus oxaliplatin (FOLFOX) $(n=150)$; uracil/tegafur $(\mathrm{UFT})+$ leucovorin $(n=2)$; and 3,4-dihydroxybenzohydroxamic acid (DIDOX) $(n=5)$. A multivariate Cox regression analysis did not identify any regimen that yielded superior DFS outcomes relative to the no-CT group. However, the XELOX/FOLFOX, UFT + leucovorin, and DIDOX regimens were associated with better OS (Table S1).

\section{Discussion}

Initially, we hypothesized that a patient with colon cancer with solitary LN metastasis would achieve a minimal survival benefit from adjuvant $\mathrm{CT}$ if adequate $\mathrm{LN}$ dissection was achieved during curative surgery. However, we observed an association of adjuvant $\mathrm{CT}$ with improved OS, but not improved DFS. In this study, patients who received adjuvant CT were significantly younger and healthier and had a higher frequency of salvage treatment for recurrence, compared to those who did not receive adjuvant CT. Still, we doubt that the improved OS in patients who received adjuvant $\mathrm{CT}$ was attributable to a younger age and better health status, rather than chemotherapy itself.

Suzuki et al. [7] suggested that the number of metastatic nodes may be a better independent prognostic factor for colorectal cancer than the locations of positive nodes. In contrast, Tang et al. [8] reported that both the number and locations of metastatic nodes were independent prognostic factors for survival in 538 patients with stage III colorectal cancer. Several other studies reported that intermediate or apical LN metastases, rather than pericolic LN metastases, were associated with compromised DFS and OS $[9,10]$. However, most previous studies included patients with rectal cancers and/or with multiple positive nodes. In contrast, our Cox regression analysis of colon cancer patients with solitary lymph node metastasis revealed no significant association between prognosis and the location of the positive LN. We further investigated the effect of the extent of LN dissection in 239 and 42 patients who underwent D3 and D2 LN dissection, respectively, but found no associations with DFS and OS. We note that the small number of patients in the D2 LN dissection group might be a source of bias. However, many previous studies reported that solitary LN metastases were most frequently detected near the primary tumor, and the efficacy of routine D3 LN dissection for colon cancer remains controversial [10-12]. 
Table 2 Univariate and multivariate analysis for disease-free survival

\begin{tabular}{|c|c|c|c|c|c|c|}
\hline \multirow[t]{2}{*}{ Variable } & \multicolumn{3}{|c|}{ Univariate analysis } & \multicolumn{3}{|c|}{ Multivariate analysis } \\
\hline & HR & $95 \% \mathrm{CI}$ & $p$ & HR & $95 \% \mathrm{CI}$ & $p$ \\
\hline \multicolumn{7}{|l|}{ Clinicopathological factor } \\
\hline Age ( $\geq 70$ years old $)$ & 1.332 & $0.713-2.487$ & 0.368 & & & \\
\hline Gender (female) & 0.979 & $0.526-1.822$ & 0.946 & & & \\
\hline BMI ( $\geq 25)$ & 0.613 & $0.300-1.254$ & 0.180 & & & \\
\hline ASA (III, IV) & 0.386 & $0.053-2.814$ & 0.347 & & & \\
\hline Tumor size $(\geq 4 \mathrm{~cm})$ & 2.146 & $1.022-4.509$ & 0.044 & 2.273 & $1.060-4.876$ & 0.035 \\
\hline Tumor sidedness (left) & 0.814 & $0.136-1.518$ & 0.518 & & & \\
\hline Preoperative CEA level (> $5 \mathrm{ng} / \mathrm{ml}$ ) & 1.784 & $0.958-3.320$ & 0.068 & 1.976 & $1.012-3.856$ & 0.046 \\
\hline Cell type (PD/MUC) & 1.393 & $0.429-4.525$ & 0.581 & & & \\
\hline pT category $(\mathrm{p} 3,4)$ & 2.028 & $0.722-5.702$ & 0.180 & & & \\
\hline LVI & 1.195 & $0.597-2.392$ & 0.616 & & & \\
\hline PNI & 1.373 & $0.738-2.554$ & 0.317 & & & \\
\hline Obstruction or perforation & 1.544 & $0.550-4.340$ & 0.410 & & & \\
\hline \multicolumn{7}{|l|}{ LN status } \\
\hline Examined $\mathrm{LN}$ counts $(\geq 12)$ & 0.520 & $0.217-1.248$ & 0.143 & 0.340 & $0.132-0.876$ & 0.025 \\
\hline D3 LN dissection (vs D2) & 1.340 & $0.940-1.910$ & 0.106 & & & \\
\hline Location of positive LN (intermediate/apical) & 1.806 & $0.859-3.795$ & 0.119 & 2.080 & $0.979-4.416$ & 0.057 \\
\hline Adjuvant chemotherapy & 0.720 & $0.282-1.840$ & 0.493 & & & \\
\hline
\end{tabular}

ASA American Society of Anesthesiologists, $P D$ poorly differentiated, $M U C$ mucinous carcinoma, $L V I$ lymphovascular invasion, $P N I$ perineural invasion, $C E A$ carcinoembryonic antigen, $L N M$ lymph node metastasis

* Significant $P$ values $(<0.05)$ are in italics

Particularly, D3 LN dissection would be less effective for a case involving solitary LN metastasis than for other cases of stage III colon cancer, given the minimal tumor burden in the lymphatic system in the former cases.

The number of harvested LNs has been reported to reflect the accuracy of staging and adequacy of surgery. Accordingly, the American Joint Committee on Cancer recommends harvesting $\geq$ 12 LNs from colon cancer patients who undergo curative intentto-treat surgery. Moreover, many studies have reported a significant correlation between a high $\mathrm{LN}$ ratio (LNR) and increased survival [13-15]. However, the LNR may be influenced by many factors, including the patient's age, tumor size, Dukes' stage, preoperative radiotherapy, operative urgency, specimen length, pathology template, and academic status of the hospital, and many cut-off values have been used for the optimal classification of subgroups according to survival [14]. Our multivariate analysis did not identify any positive effect of adjuvant CT on DFS outcomes when $>12$ LNs were examined (Table 2), and this phenomenon remained consistent at different $\mathrm{LN}$ counts $(8,12$, 20, and 30) (Table S2). Moreover, we did not observe an association between adjuvant CT and DFS according to the extent of LN dissection (D2 vs. D3) (Table S2).

Previously, few treatment options were available for metastatic disease. More recently, increased rates of R0 salvage resection and new palliative CT options, including anti-vascular endothelial growth factor monoclonal IgG1 antibodies and epidermal growth factor receptor inhibitors, have significantly prolonged survival durations from approximately 12 months to 2 years. Historically, improved OS has been the gold standard used to define survival benefits from adjuvant and palliative CT. However, DFS has been recommended recently as an appropriate endpoint for defining benefit from adjuvant $\mathrm{CT}$, as OS can be heavily influenced by patient characteristics and the salvage treatment status $[16,17]$. Adjuvant FOLFOX was improved for the treatment of advanced colorectal cancer in the USA after the Multicenter International Study of Oxaliplatin/5-Fluorouracil/ leucovorin in the Adjuvant Treatment of Colon Cancer (MOSAIC) trial demonstrated significant improvements in 3year DFS [18]. In that study, however, adjuvant FOLFOX did not yield improvements in OS relative to the control arm, which the researchers explained as a consequence of the frequency of salvage treatments [16]. In our study, we observed an association of adjuvant CT with improved OS but not improved DFS in colon cancer patients with solitary LN metastasis. Although the $\mathrm{CT}$ and no-CT groups had similar recurrence rates, a significantly high proportion of patients in the former group received salvage treatments for recurrence. The improved OS in the CT group may therefore be a result of the high rates of salvage treatments for recurrence.

Our sub-group analysis of the effects of CT regimen on prognosis revealed improvements in OS among patients treated with oxaliplatin-containing regimens, but not among those 
Table 3 Univariate and multivariate analysis for overall survival

\begin{tabular}{|c|c|c|c|c|c|c|}
\hline \multirow[t]{2}{*}{ Variable } & \multicolumn{3}{|c|}{ Univariate analysis } & \multicolumn{3}{|c|}{ Multivariate analysis } \\
\hline & HR & $95 \% \mathrm{CI}$ & $p$ & $\mathrm{HR}$ & $95 \% \mathrm{CI}$ & $p$ \\
\hline \multicolumn{7}{|l|}{ Clinicopathological factor } \\
\hline Age ( $\geq 70$ years old $)$ & 3.181 & $1.757-5.756$ & $<.001$ & 2.278 & $1.192-4.354$ & 0.013 \\
\hline Gender (female) & 0.850 & $0.477-1.512$ & 0.580 & & & \\
\hline $\mathrm{BMI}(\geq 25)$ & 0.642 & $0.334-1.235$ & 0.184 & & & \\
\hline ASA (III, IV) & 2.751 & $1.278-5.923$ & 0.010 & 2.093 & $0.960-4.563$ & 0.063 \\
\hline Tumor size $(\geq 4 \mathrm{~cm})$ & 2.674 & $1.294-5.524$ & 0.008 & 2.597 & $1.217-5.543$ & 0.014 \\
\hline Tumor sidedness (left) & 0.907 & $0.511-1.611$ & 0.739 & & & \\
\hline Preoperative CEA level (> $5 \mathrm{ng} / \mathrm{ml}$ ) & 2.900 & $1.625-5.174$ & $<.001$ & 1.871 & $1.010-3.466$ & 0.047 \\
\hline Cell type (PD/MUC) & 1.670 & $0.597-4.667$ & 0.328 & & & \\
\hline $\mathrm{pT}$ category $(\mathrm{p} 3,4)$ & 2.538 & $0.911-7.068$ & 0.075 & & & \\
\hline LVI & 1.500 & $0.823-2.735$ & 0.185 & 1.924 & $1.039-3.565$ & 0.037 \\
\hline PNI & 1.768 & $1.002-3.120$ & 0.049 & 2.005 & $1.094-3.646$ & 0.024 \\
\hline Obstruction or perforation & 1.532 & $0.607-3.869$ & 0.367 & & & \\
\hline \multicolumn{7}{|l|}{ LN status } \\
\hline Examinined LN counts $(\geq 12)$ & 1.313 & $0.468-3.685$ & 0.605 & & & \\
\hline D3 LN dissection (vs D2) & 1.186 & $0.531-2.650$ & 0.677 & & & \\
\hline Location of positive LN (intermediate/apical) & 0.653 & $0.258-1.649$ & 0.367 & & & \\
\hline Adjuvant chemotherapy & 0.262 & $0.138-0.497$ & $<.001$ & 0.379 & $0.180-0.797$ & 0.011 \\
\hline
\end{tabular}

ASA American Society of Anesthesiologists, $P D$ poorly differentiated, $M U C$ mucinous carcinoma, $L V I$ lymphovascular invasion, $P N I$ perineural invasion, $C E A$ carcinoembryonic antigen, $L N M$ lymph node metastasis

* Significant $P$ values $(<0.05)$ are in italics

treated with 5-FU/leucovorin-containing regimens. We note that oxaliplatin-containing regimens are generally selected for younger patients with a favorable performance status, as they would be better able to withstand the associated toxicity. Possibly, therefore, the observed improvements in OS might be attributed to differences in the patients' characteristics, such as a young age and good performance status, rather than the type of CT regimen.

This study had several limitations of note. First, the retrospective design may have introduced selection bias. Second,

Table 4 Recurrence rate and salvage treatment for recurrence

\begin{tabular}{|c|c|c|c|}
\hline & Adjuvant CT (-) & Adjuvant CT (+) & $p$ \\
\hline Recurrence rate, $n(\%)$ & $5(12.8 \%)$ & $35(14.5 \%)$ & 1.000 \\
\hline \multicolumn{4}{|l|}{ Pattern, $n(\%)$} \\
\hline $\begin{array}{l}\text { Local } \pm \text { distant } \\
\text { Distant only }\end{array}$ & $\begin{array}{l}0 \\
5(100 \%)\end{array}$ & $\begin{array}{l}2(5.7 \%) \\
33(94.3 \%)\end{array}$ & 1.000 \\
\hline \multicolumn{4}{|c|}{ Treatment for recurrence, $n(\%)$} \\
\hline $\begin{array}{l}\text { BSC } \\
\text { Any treatment }{ }^{a}\end{array}$ & $\begin{array}{l}4(80 \%) \\
1(20 \%)\end{array}$ & $\begin{array}{l}3(8.6 \%) \\
32(91.4 \%)\end{array}$ & 0.002 \\
\hline
\end{tabular}

$B S C$ best supportive care

${ }^{a}$ Refer to any regimen of chemotherapy, surgical resection, radiofrequency ablation, radiation therapy

*Significant $P$ values $(<0.05)$ are in italics the small number of patients in the no-CT group may have led to an underpowered statistical analysis. Third, the differences in follow-up periods between the two groups might have introduced bias with respect to the recurrence rate and survival outcomes. Still, we note that most of recurrences of colorectal cancer after radical surgery occur within 2 years postoperatively. The 2-year DFS and OS outcomes in our study did not differ from the 5-year DFS and OS outcomes in this study.

Despite these limitations in this study, our analysis includes almost all clinicopathological and surgical factors that may be associated with the prognosis of colon cancer patients who underwent radical surgery. We also performed several analyses to verify the effects of adjuvant CT on the survival outcomes of the colon cancer patients with solitary LN metastasis and determined that the general administration of adjuvant CT for colon cancer with solitary LN metastasis might have led to overtreatment in some cases. Given the lack of definitive methods to detect metastatic lymph nodes preoperatively, however, it would be unreasonable to change the present treatment policy or to omit adjuvant $\mathrm{CT}$ when treating patients with suspected solitary LN metastasis. Until our results can be validated through larger-scale studies, we believe that the existing treatment strategy should be retained. Several other pathologic and molecular risk factors associated with prognosis should also be studied in depth. 


\section{Conclusions}

The survival benefit of adjuvant CT for colon cancer with solitary LN metastasis remained unclear, in contrast to other stage III cancers. If subsequent larger studies verify our findings, decisions regarding adjuvant $\mathrm{CT}$ administration for patients with solitary LN metastasis should consider various risk factors, as is currently done for stage II cancers. Further validation through large studies of molecular markers associated with the biology of colon cancer is also necessary.

Funding This study was supported by a grant (HCRI 190005) Chonnam National University Hwasun Hospital Institute for Biomedical Science.

\section{Compliance with ethical standards}

Ethics approval and informed consent All procedures were performed in adherence to the ethical standards of the institutional research committee and the 1964 Declaration of Helsinki and its later amendments or comparable ethical standards. The Institutional Review Board of Chonnam National University Hwasun Hospital, Hwasun-gun, South Korea, approved the study (reference number CNUHH-2019-015); this study was eligible for exemption of informed consent. No animal experiments were performed in this study.

Conflict of interest The authors declare that they have no conflict of interest.

Open Access This article is distributed under the terms of the Creative Commons Attribution 4.0 International License (http:// creativecommons.org/licenses/by/4.0/), which permits unrestricted use, distribution, and reproduction in any medium, provided you give appropriate credit to the original author(s) and the source, provide a link to the Creative Commons license, and indicate if changes were made.

\section{References}

1. Chu QD, Zhou M, Medeiros K, Peddi P (2016) Positive surgical margins contribute to the survival paradox between patients with stage IIB/ C (T4N0) and stage IIIA (T1-2N1, T1N2a) colon cancer. Surgery 160(5):1333-1343. https://doi.org/10.1016/j.surg.2016.05.028

2. Kim MJ, Jeong SY, Choi SJ, Ryoo SB, Park JW, Park KJ, Oh JH, Kang SB, Park HC, Heo SC, Park JG (2015) Survival paradox between stage IIB/C (T4N0) and stage IIIA (T1-2N1) colon cancer. Ann Surg Oncol 22(2):505-512. https://doi.org/10.1245/s10434-014-3982-1

3. Rottoli M, Stocchi L, Dietz DW (2012) T4N0 colon cancer has oncologic outcomes comparable to stage III in a specialized center. Ann Surg Oncol 19(8):2500-2505. https://doi.org/10.1245/s10434-012-2292-8

4. Bertelsen CA, Kirkegaard-Klitbo A, Nielsen M, Leotta SM, Daisuke F, Gogenur I (2016) Pattern of Colon Cancer lymph node metastases in patients undergoing central Mesocolic lymph node excision: asystematic review. Dis Colon Rectum 59(12):12091221. https://doi.org/10.1097/dcr.0000000000000658

5. Morris EJ, Maughan NJ, Forman D, Quirke P (2007) Who to treat with adjuvant therapy in dukes B/stage II colorectal cancer? The need for high quality pathology. Gut 56(10):1419-1425. https://doi. org/10.1136/gut.2006.116830

6. Daly MC, Paquette IM (2019) Surveillance, epidemiology, and end results (SEER) and SEER-Medicare databases: use in clinical research for improving colorectal Cancer outcomes. Clin Colon Rectal Surg 32(1):61-68. https://doi.org/10.1055/s-0038-1673355

7. Suzuki O, Sekishita Y, Shiono T, Ono K, Fujimori M, Kondo S (2006) Number of lymph node metastases is better predictor of prognosis than level of lymph node metastasis in patients with node-positive colon cancer. J Am Coll Surg 202(5):732-736. https://doi.org/10.1016/j.jamcollsurg.2006.02.007

8. Tang R, Wang JY, Chen JS, Chang-Chien CR, Tang S, Lin SE, You YT, Hsu KC, Ho YS, Fan HA (1995) Survival impact of lymph node metastasis in TNM stage III carcinoma of the colon and rectum. J Am Coll Surg 180(6):705-712

9. Huh JW, Kim YJ, Kim HR (2012) Distribution of lymph node metastases is an independent predictor of survival for sigmoid colon and rectal cancer. Ann Surg 255(1):70-78. https://doi.org/10.1097/ SLA.0b013e31823785f6

10. Kim JC, Lee KH, Yu CS, Kim HC, Kim JR, Chang HM, Kim JH, Kim JS, Kim TW (2004) The clinicopathological significance of inferior mesenteric lymph node metastasis in colorectal cancer. Eur J Surg Oncol 30(3):271-279. https://doi.org/10.1016/j.ejso.2003.12.002

11. Bertelsen CA, Neuenschwander AU, Jansen JE, Wilhelmsen M, Kirkegaard-Klitbo A, Tenma JR, Bols B, Ingeholm P, Rasmussen LA, Jepsen LV, Iversen ER, Kristensen B, Gögenur I, Danish Colorectal Cancer Group (2015) Disease-free survival after complete mesocolic excision compared with conventional colon cancer surgery: a retrospective, population-based study. Lancet Oncol 16(2):161-168. https://doi.org/10.1016/s1470-2045(14)71168-4

12. Matsuda K, Yokoyama S, Hotta T, Takifuji K, Watanabe T, Tamura K, Mitani Y, Iwamoto H, Mizumoto Y, Yamaue H (2017) Oncological outcomes following rectal Cancer surgery with high or low ligation of the inferior mesenteric artery. Gastrointest Tumors 4(1-2):45-52. https://doi.org/10.1159/000477805

13. Schumacher P, Dineen S, Barnett C Jr, Fleming J, Anthony $\mathrm{T}$ (2007) The metastatic lymph node ratio predicts survival in colon cancer. Am J Surg 194(6):827-831; discussion 831-822. https://doi. org/10.1016/j.amjsurg.2007.08.030

14. Akagi Y, Adachi Y, Kinugasa T, Oka Y, Mizobe T, Shirouzu K (2013) Lymph node evaluation and survival in colorectal cancer: review of population-based, prospective studies. Anticancer Res 33(7):2839-2847

15. Ceelen W, Van Nieuwenhove Y, Pattyn P (2010) Prognostic value of the lymph node ratio in stage III colorectal cancer: a systematic review. Ann Surg Oncol 17(11):2847-2855. https://doi.org/10. 1245/s10434-010-1158-1

16. Sargent DJ, Patiyil S, Yothers G, Haller DG, Gray R, Benedetti J, Buyse M, Labianca R, Seitz JF, O'Callaghan CJ, Francini G, Grothey A, O'Connell M, Catalano PJ, Kerr D, Green E, Wieand HS, Goldberg RM, de Gramont A, ACCENT Group (2007) End points for colon cancer adjuvant trials: observations and recommendations based on individual patient data from 20,898 patients enrolled onto 18 randomized trials from the ACCENT group. J Clin Oncol 25(29):4569-4574. https://doi.org/10.1200/jco.2006.10.4323

17. Punt CJ, Buyse M, Kohne CH et al (2007) Endpoints in adjuvant treatment trials: a systematic review of the literature in colon cancer and proposed definitions for future trials. J Natl Cancer Inst 99(13): 998-1003. https://doi.org/10.1093/jnci/djm024

18. André T, Boni C, Mounedji-Boudiaf L, Navarro M, Tabernero J, Hickish T, Topham C, Zaninelli M, Clingan P, Bridgewater J, TabahFisch I, de Gramont A, Multicenter International Study of Oxaliplatin/ 5-Fluorouracil/Leucovorin in the Adjuvant Treatment of Colon Cancer (MOSAIC) Investigators (2004) Oxaliplatin, fluorouracil, and Leucovorin as adjuvant treatment for Colon Cancer. N Engl J Med 350(23):2343-2351. https://doi.org/10.1056/NEJMoa032709

Publisher's note Springer Nature remains neutral with regard to jurisdictional claims in published maps and institutional affiliations. 